\title{
The impact of introduced hosts on parasite transmission: opisthorchiid infections in American mink (Neovison vison)
}

\author{
Ellie Sherrard-Smith • Elizabeth A. Chadwick • \\ Jo Cable
}

Received: 26 September 2013/Accepted: 2 May 2014/Published online: 10 May 2014

(C) The Author(s) 2014. This article is published with open access at Springerlink.com

\begin{abstract}
Introduced animals may be considered at an advantage over native competitors because they have escaped natural parasites. In some cases however, generalist parasites in a novel environment can use introduced species as an alternative or reservoir host. This can change the dynamics of parasite populations, with implications for epidemiology. The key factor determining the impact of an alternative host is its ability to maintain a reproductively successful parasite and contribute to the transmission potential of that parasite. The digenean Pseudamphistomum truncatum is found in native otters Lutra lutra in Britain and has been reported in introduced American mink Neovison vison. To investigate whether introduced mink are competent hosts and to ask how mink compare with otters as hosts, we compared parasite prevalence, intensity and fecundity between the two host species in a region where both are common. Although prevalence was not statistically different between otters and mink (48\%, $\mathrm{n}=27$, compared to $33 \%, \mathrm{n}=21$ respectively), mean parasite intensity was higher in mink $(253 \pm 145$ standard error parasites/infected host, compared to $46 \pm 18$ in otters). Parasite fecundity was lower in mink (mean egg count/parasite/ host $=622 \pm 64)$ than in otters $(1,204 \pm 108)$, and
\end{abstract}

E. Sherrard-Smith $(\square) \cdot$ E. A. Chadwick · J. Cable School of Biosciences, Cardiff University, Museum Avenue, Cardiff CF10 3AX, UK

e-mail: ellie.sherrard-smith@phe.gov.uk this difference was not confounded by host or parasite size or by intraspecific competition among parasites. Assuming the parasite eggs are equally viable from otters or mink, mink are not only a competent host for $P$. truncatum, but because of the higher parasite intensity in mink, they can potentially spread c. 3 times as many parasite eggs to intermediate hosts, than otters. The naturalisation of mink to new habitats may therefore contribute to trematode infections in native fauna.

Keywords Host-parasite introductions .

Transmission potential · Parasite fecundity .

Parasite spillback

\section{Introduction}

The role of invading hosts as reservoirs for infectious disease can have severe, negative impacts on native hosts (Bonhoeffer et al. 1996; Halliwell and Macdonald 1996; Daszak et al. 2000; Macdonald and Harrington 2003; Bonesi and Palazon 2007). The introduction of a non-native species that is a competent host for a native parasite can cause an increase in disease, a process termed 'parasite spillback' (Kelly et al. 2009). In contrast, where introduced species are not viable hosts for a given infection, a dilution effect can operate through the termination of parasitic infectious agents within 'dead end' hosts (Johnson et al. 2009; Keesing et al. 2010). The global movement 
of humans and associated resources creates an elevated potential for interaction between parasites and hosts that were previously geographically separated (reviewed in Ricciardi 2007). Generally, parasites are reported to do better within a native rather than an introduced host—with higher parasite species richness and higher abundance recorded in native host populations (Dunn and Dick 1998; Roche et al. 2010; Gendron et al. 2012; Lacerda et al. 2012; Ondračková et al. 2012) — but this is not always the case (Vale et al. 1991; Pasternak et al. 2007). The traits associated with parasite fitness such as parasite abundance can, on occasion, be higher in introduced host species (Kennedy et al. 1991; Rauque et al. 2003).

Indirect consequences of introductions can include impacts on the competitive ability of similar species, through differences in their tolerance of parasites (e.g. Povilitis 1998; Coombes 2001). American mink, Neovison vison, are associated with declines of water voles Arvicola amphibius and birds in the UK due to predation (Ferreras and Macdonald 1999; Barreto and Macdonald 2000; Bonesi and Palazon 2007) but mink may also cause problems through their ability to act as reservoir hosts for endemic disease (Nituch et al. 2011). For instance, the transfer of Aleutian disease (caused by a highly pathogenic parovirus) from domesticated American mink to wild counterparts has contributed to the decline of wild mink populations in Canada (Nituch et al. 2011). Understanding how competent introduced hosts will impact on vulnerable native species will help conservation efforts, and pinpointing the contribution that these introduced hosts make towards parasite transmission is key to our understanding of disease dynamics.

In the current study, we compare populations of the opisthorchiid parasite Pseudamphistomum truncatum infecting the introduced American mink $N$. vison (hereafter referred to as mink) and the native Eurasian otter Lutra lutra (hereafter referred to as otter) in Somerset, UK. Both mink and otters are carnivorous mammals (Family Mustelidae) with similar natural ranges bridging both freshwater and terrestrial habitats and both species are distributed widely across the UK (Bonesi et al. 2004; Harris and Yalden 2008). The otter (mean body mass males $=10.1 \mathrm{~kg}$, females $=7.0 \mathrm{~kg}$; Harris and Yalden 2008) can outcompete the smaller mink (mean body mass males $=1.2 \mathrm{~kg}$, females $=0.64 \mathrm{~kg}$; Harris and Yalden 2008) where ranges overlap (Bonesi et al. 2004). Even so, American mink are now naturalised across most of Europe (Jeschke and Strayer 2005) and wild populations have been established in the Somerset area since the 1950s (Bonesi and Palazon 2007). In their native range of North America, mink can host many helminth parasites (Erickson 1946; Barber and Lockard 1973) including the opisthorchiid Metorchis conjunctus (see Erickson 1944, 1946) which, like P. truncatum, occupies the definitive host gall bladder. The mink has however no historic interaction with $P$. truncatum because the parasite is absent from North America.

Pseudamphistomum truncatum has a debatable history in the UK but recent research by the authors (unpublished) supports a long-term residency. Further, $P$. truncatum is a generalist trematode with the potential to infect any piscivorous vertebrate. The geographic range of the parasite in England and Wales is patchy, but it is most abundant in South Wales, Dorset and Somerset (Sherrard-Smith et al. 2009). Significant pathological damage to the gall bladder is reported (Simpson et al. 2005). In the current study, we aim to establish whether mink are a competent host for $P$. truncatum and ask whether these parasites have a different transmission potential in this introduced host compared to the native otter.

\section{Materials and methods}

Mink $(\mathrm{n}=21)$ were trapped and shot in the Somerset and Severn Estuary regions of England and Wales during 2010-2012, as part of a control program. Mink carcasses, and those of otters $(n=27)$ found dead (primarily as a result of road traffic accident) in Somerset during the same period were donated to the Cardiff University Otter Project (CUOP) for post mortem examination. Biases in infection due to differences in sampling regime cannot be ruled out, but are thought to be unlikely. Location information was provided with the carcasses, and host sex and morphological data (length and body mass) were recorded by CUOP. The gall bladders were retained during post mortem examination. Gall bladders were dissected using a Nikon light microscope with fibre optic illumination and $20 \times$ magnification and parasites were identified morphologically following Yamaguti (1971) and confirmed molecularly using the internal transcribed spacer II (ITSII) region of ribosomal DNA (Sherrard-Smith et al. 2009). The 
presence or absence of parasites, the intensity of any infections, the species, and associated damage to the gall bladder were recorded. Pathology of the gall bladder can be assessed visually on a scale of 1-5; ranging from a healthy gall bladder (1) to significant pathology evidenced as a highly fibrous and thickened organ (5) (following Sherrard-Smith et al. 2009).

Parasite fecundity is defined as the rate of egg release per unit time over the reproductive lifetime of the parasite and, for helminths, is usually measured using faecal egg counts (Madhavi 1979; Rolfe et al. 1991), but the number of reproductive units (eggs) within the uterus can be used as a proxy for helminth fecundity where faecal data are unavailable (Richards and Lewis 2001). A random sample of the parasite population (10 worms from each host, 7 infected mink and 13 infected otters) was screened to estimate the mean fecundity of parasites per host. Each parasite was flat fixed in deionised water between two square glass plates for $4 \mathrm{~h}$ under constant pressure, and then photographed (Nikon dissecting microscope with $40 \times$ magnification and Caplio R4 camera illuminated by fibre optic source) and measured (length, width and surface area) using ImageJ (version 1.42, Schneider et al. 2012). Both the high number of eggs and the tendency of these parasite eggs to cluster in solution renders egg counts using traditional methods such as McMaster's inaccurate (e.g. Ward et al. 1997). Instead, each parasite was teased apart in $2 \mathrm{ml}$ of distilled water within an adapted microscope slide, with a $2 \mathrm{~mm}$ high rim surrounding a $15 \mathrm{~mm}^{2}$ central arena. The slide was scanned at $400 \times$ magnification and c.500 images were taken of each slide to cover the $15 \mathrm{~mm}^{2}$ area in fine detail. These images were consecutive, without overlap of adjacent images, and were screened manually, counting all eggs touching or crossing the top and left edge and ignoring those on the bottom and right edge of each image, to avoid counting eggs twice. This allowed an accurate estimate of the in utero egg count for each parasite.

\section{Statistical analysis}

The prevalence of parasites in each host species was compared using a binomial test. Further analyses were used to test differences between otters and minks in parasite size, intensity of infection and individual parasite fecundity, as follows.
Larger hosts tend to have larger parasites and larger parasites are often more fecund (Poulin 1997) so the difference in size between parasites from otters and mink was examined using analysis of variance (ANOVA). Two measures of host size (mass, length) were highly correlated $(\mathrm{r}=0.956)$ and therefore could not be included in the same models. Instead, a host size index was calculated incorporating both terms, while taking into account the larger size of the otters (for mink: host mass $\times$ length; otters: host mass $\times$ length)/4). To consider whether there was a relationship between host species and parasite intensity, while controlling for host size differences, a general linear model (GLM) with a negative binomial error distribution was fitted to the parasite intensity data, with host species, host size index, and their interaction, as explanatory variables.

To test whether intraspecific competition might negatively impact the parasite, a general linear model with a negative binomial error distribution was fitted to the parasite intensity data with parasite width, length and area, as proxies for parasite size (separate models were used for each parasite size measure because of collinearity), included as explanatory variables. Host species was included as a fixed term in each model.

To examine whether the number of eggs per parasite (individual parasite fecundity) is associated with host species, a random intercept model was fitted to the individual parasite egg counts, with the parasite width and host species as fixed effects and the individual host as a random effect (using the nlme package in $\mathrm{R}$ version 3.0; lme with a log transformation). Parasite width was preferred to other measures because it was the best predictor of egg number in comparison to parasite length and area.

A per capita yield of each host species was calculated to represent the ultimate number of eggs within each host i.e. the intensity of parasites multiplied by the mean egg count per parasite per host. This would allow us to compare the contribution of each host species to the spread of the parasite.

Host sex was not included in any of the models because the sample sizes of infected hosts was too small (only $2 / 7$ infected mink were female). All statistical analyses were performed in $\mathrm{R}$ version 12.2 (R Core Development Team 2010). 
Table 1 Summary statistics contrasting Pseudamphistomum truncatum in mink and otters

\begin{tabular}{|c|c|c|c|}
\hline & Mink & Otter & $\begin{array}{l}\text { Significant } \\
\text { difference }\end{array}$ \\
\hline Prevalence & $33 \%(\mathrm{n}=21)$ & $48 \%(n=27)$ & No \\
\hline $\begin{array}{l}\text { Parasite intensity: mean } \pm \text { standard error } \\
\text { (range) }\end{array}$ & $253 \pm 145(5-1,000)$ & $46 \pm 18(2-243)$ & Yes \\
\hline $\begin{array}{l}\text { Parasite fecundity: mean } \pm \text { standard error } \\
\text { (range) }\end{array}$ & $622 \pm 64(62-2,235)$ & $1,204 \pm 108(85-2,639)$ & Yes \\
\hline $\begin{array}{l}\text { Parasite width: mean } \pm \text { standard error } \\
\text { (range) }\end{array}$ & $0.44 \pm 0.014(0.199-0.718) \mathrm{mm}$ & $0.50 \pm 0.018(0.175-0.95) \mathrm{mm}$ & Yes \\
\hline $\begin{array}{l}\text { Parasite length: mean } \pm \text { standard error } \\
\text { (range) }\end{array}$ & $1.70 \pm 0.046(0.978-2.461) \mathrm{mm}$ & $1.99 \pm 0.044(1.146-2.741) \mathrm{mm}$ & Yes \\
\hline $\begin{array}{l}\text { Parasite area: mean } \pm \text { standard error } \\
\text { (range) }\end{array}$ & $0.69 \pm 0.038(0.199-1.677) \mathrm{mm}^{2}$ & $0.95 \pm 0.060(0.276-2.40) \mathrm{mm}^{2}$ & Yes \\
\hline $\begin{array}{l}\text { Mean per capita yield: mean } \pm \text { standard } \\
\text { error (range) }\end{array}$ & $\begin{array}{l}1.8 \times 10^{+5} \pm 9.1 \times 10^{+4} \\
\quad(1,521-678,285)\end{array}$ & $\begin{array}{l}3.9 \times 10^{+4} \pm 1.2 \times 10^{+4} \\
\quad(3,869-142,533)\end{array}$ & Yes \\
\hline
\end{tabular}

\section{Results}

The prevalence of $P$. truncatum in mink was $33 \%$ (7 of 21 animals) compared to $48 \%$ in otters (13 of 27 animals) but this difference was not significant [Binomial test: 0.33 (95\% confidence intervals 29-68 \%), $p=0.107]$. Parasites were smaller in mink than in otters [ANOVA parasite width: $\mathrm{F}=6.16$, MSS $=0.12, \quad d f=1, \quad p<0.05 ;$ parasite length: $\mathrm{F}=19.19, \mathrm{MSS}=2.80, d f=1, p<0.0001 ;$ and parasite area: $\mathrm{F}=10.51$, mean sum of squares $(\mathrm{MSS})=2.29, d f=1, p<0.005$; see Table 1].

The mean intensity of $P$. truncatum in mink (253 parasites per infected host \pm 145 standard error) was significantly higher than that in otters $(46 \pm 18)$ (GLM: $\quad$ AIC $=192.27, \chi^{2}=6.12$, standard error $0.55, d f=1, p<0.05$ ). Neither host size index, nor the interaction between host species and size, were significantly associated with parasite intensity $(p>0.1)$.

Parasite intensity was higher when parasites were smaller, such that intensity was associated with parasite area (GLM: AIC $=188.90, \chi^{2}=4.06$, standard error $0.52, d f=19, p<0.05)$ but not with parasite width (GLM: AIC $=189.90, \chi^{2}=2.89$, standard error 1.97, $d f=19, p=0.09$ ) or length (GLM: $\quad$ AIC $=190.56, \chi^{2}=2.14$, standard error $0.53, d f=19, p=0.14)$.

There was a significant difference in parasite fecundity between otters and mink with otters having slightly more eggs per parasite than mink (GLM AIC:

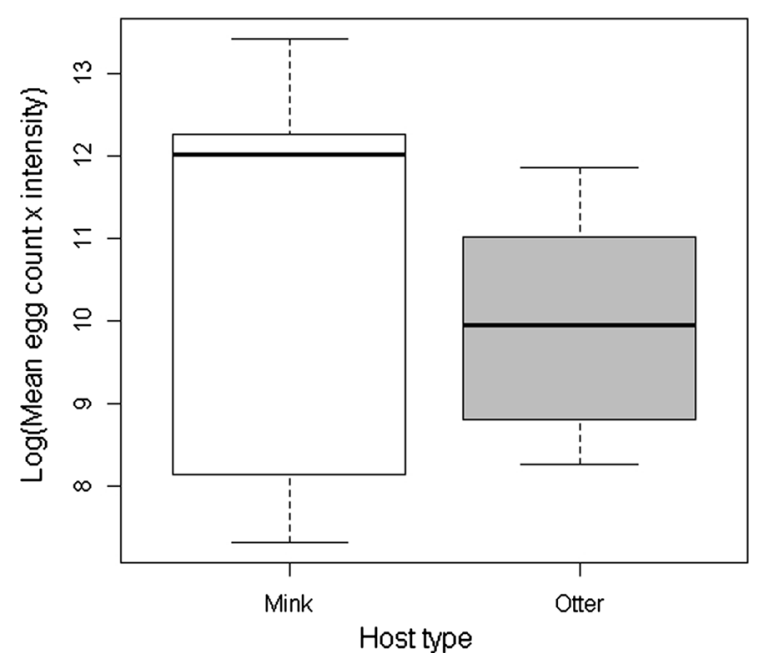

Fig. 1 The ultimate contribution to reproductive parasitic units for Pseudamphistomum truncatum in introduced American mink Neovison vison and native Eurasian otters Lutra lutra. Parasite intensity multiplied by the mean number of eggs per parasite per host (log transformed) for each host type is shown, the mean count is marked as a dark line, boxes indicate standard error and dashed lines indicate 95 percentiles

273.61, $\quad \mathrm{t}=2.578, \quad$ standard $\quad$ error $=0.1122$, $p<0.05)$. There was a significant association between parasite width and parasite fecundity such that wider parasites had more eggs (GLM AIC: 273.61, $\mathrm{t}=5.656$, standard error $=0.1886, p<0.001)$.

When the per capita yield (intensity $\times$ mean number of eggs per parasite per host) was compared between host species, a significantly greater potential 
contribution of parasite eggs (infective stages) to the environment was associated with the introduced mink population (Fig. $1 ; \mathrm{F}=4.619, d f=18, p=0.0455$ ).

\section{Discussion}

Introduced hosts can exert subtle impacts on native fauna, for example, causing an increase in disease due to the availability of an additional competent host species (Kelly et al. 2009). In the current study, introduced mink are shown to be competent hosts for $P$. truncatum. The introduced mink were infected to a higher intensity than native otters, and although otters harboured parasites with a higher in utero egg count than the introduced mink, once intensity of infection was taken into account the total potential contribution of parasite eggs released by mink is greater than that of native otters. If we assume that viability of parasite eggs from both hosts is equal (it was not possible to test this in the current study), then the introduced mink is the more competent host for $P$. truncatum in Somerset.

Fitness-associated traits and transmission potential for parasites are sometimes greater in introduced hosts (Kelly et al. 2009). For example, at the intermediate host level, helminths in introduced salmonids are both more abundant and in some cases more fecund than those in native counterparts (Kennedy et al. 1991). Seroprevalence of Ross River Virus in Australia was greatest in introduced horses compared to native marsupials (Kay et al. 2007), and introduced European starling Sturnis vulgaris transmitted a higher proportion of Eastern equine encephalitis virus to mosquito vectors than comparable native avian species (Komar et al. 1999). More generally, fitness-associated traits of parasites are higher in the native host (Dunn and Dick 1998; Roche et al. 2010; Gendron et al. 2012; Lacerda et al. 2012; Ondračková et al. 2012). The prevalence and abundance (or intensity) of native helminths has been compared between introduced and native definitive hosts (Kelly et al. 2009), including the American mink in Europe (Shimalov and Shimaliv 2001; Torres et al. 2003, 2008). Each of these studies indicated a paucity of helminth fauna diversity (and prevalence) in the introduced mink relative to native hosts (Torres et al. 2008). Prior to the current study, differences in macroparasite fecundity within introduced and native definitive hosts do not appear to have been explored, yet this is a fundamental aspect of parasite transmission potential. The sample sizes and geographic range of the current study are small (only 7 infected mink and 13 infected otters from Southwest England) and so our findings may have limited generality.

Episodes of wild mammalian population declines have been attributed to spillover events where a disease is maintained within a resident host, but spills over into adjacent and more susceptible, or novel species (Kock et al. 1999; Randall et al. 2006; Rudge et al. 2009; Nituch et al. 2011). This is evidenced, for example, by rabies spillover from domesticated dogs to the threatened Ethiopian wolf Canis simensis (see Randall et al. 2006), Rinderpest virus from African domesticated cattle to wild ruminants (Kock et al. 1999) and Aleutian disease (caused by a highly pathogenic parovirus) from domesticated American mink to wild counterparts (Nituch et al. 2011). In this manner, alternative host populations have been shown to act as sinks, if continually but not constantly, exposed to source viral particles from a native host (Schmidt and Ostfeld 2001; Dennehy et al. 2006).

The recent naturalisation of mink to British habitats, and their apparent competence as hosts for $P$. truncatum, is likely to contribute to an increase in abundance of trematodes in native fauna (support for parasite spillback hypothesis, Kelly et al. 2009), although it is possible that differences between host species in habitat usage (e.g. out-competition of mink by otters for semi-aquatic habitat, Harris and Yalden 2008) may reduce transmission risk. Road-killed otters have been systematically examined in Britain for nearly 30 years but the parasite was only identified in 2005 with evidence of pathology dating back to 2000 (Simpson et al. 2005). The discovery of $P$. truncatum in otters may result from increasing abundance of this parasite following the establishment of the mink population in the Somerset area in the late 1950s (Bonesi and Palazon 2007). At a population level, we cannot yet comment on how the potential increase in parasite abundance through parasite spillback via mink might be impacting on native otters. Modelling of host population dynamics suggests, however, that an increase in definitive host numbers can result in an increase in the proportion of snails and fish infected, and an increase in eggs released into the environment, while the proportion of definitive hosts infected remains constant (unpublished data). This indicates that the overall abundance of the parasite 
would increase dramatically with the availability of an additional definitive host. Theoretically, parasite evolution depends on selection pressures acting on parasite life-history traits within different hosts (Gandon 2004). Parasite fitness (egg production) may therefore be higher in otters because $P$. truncatum has co-existed for a longer period with this host than with the introduced mink, and there has been co-adaptation between the two species.

The final size of adult helminths has been related to host body mass (Poulin et al. 2003), but parasite size is not strictly determined by this factor (Brooks and McLennan 1993; Poulin et al. 2003). In general, larger parasites tend to be more fecund (Poulin 1997) and although there is a trend for larger $P$. truncatum worms to be more fecund, this does not explain the observed difference in parasite fecundity between host species in the current study. Density dependent effects are reported for other trematodes such as Paradistomum orientalis (see Madhavi et al. 1998), and parasite intensity was also associated with parasite size in $P$. truncatum indicating that there may be subtle effects of intra-specific competition in these parasites. The adult body size of helminths is linked to the size of the early life stages, regardless of the definitive host body mass (Poulin et al. 2003) and, within endothermic hosts, the ultimate size of adult parasites can be greater in hosts maintaining higher body temperatures (Atkinson 1994, 1995; Sibly and Atkinson 1994). Therefore, assuming infections of both otter and mink stem from $P$. truncatum worms sourced within the same genetic population in Somerset, with early life-stages from the same types of intermediate hosts, differences in parasite egg counts may be substantially impacted by microhabitat variation within the two definitive hosts.

Competition between otters and mink may contribute to the different parasite prevalence and intensities observed in the current study. Otters tend to outcompete mink in riverine habitats (Bonesi et al. 2004) so that fish contribute a greater proportion of the otter diet, explaining higher prevalence in the otter population. Hosts that are recently introduced to particular parasites often demonstrate greater susceptibility because of a naïve immune response (Franceschi et al. 2010) perhaps explaining the higher intensities of $P$. truncatum infection in introduced mink compared to the native otter. It is worth noting that we observed significant pathology to mink, with damage to the bile ducts and livers in the two most heavily infected cases that, to date, far exceeded anything observed in the otters. The damage had caused the gall bladders of the mink to become extremely fibrous and shrunken potentially causing morbidity and reduced competitive ability in these mink. Perhaps otters are better able to sequester the parasites within the gall bladder organ and this may act, to some degree, as an adaptive defensive mechanism to protect the liver. Total egg yield per host will depend on longevity of the infected host, a variable we could not measure here. There is theoretical evidence that greater propagule (egg) longevity may initially favour higher virulence for parasites that have recently invaded a susceptible host population (Bonhoeffer et al. 1996). Equally, if virulence was too high then disease 'burn out' may result. If these parasites are causing high levels of damage and morbidity in the mink then the higher virulence may indicate the recent invasion of the mink as a host. Alternatively, (and even though the parasites appear to have a higher per capita yield in mink) if the parasite causes the mink to become less competitive then the overall contribution to parasite abundance would be limited.

The current study is to our knowledge, one of the first to compare the in utero fecundity of parasites infecting native and introduced definitive host populations. This study provides an insight into the difference in transmission potential of a parasite within naïve and established hosts, and highlights a hidden cost of biological invasions.

Acknowledgments We thank the Environment Agency for providing mink and otter carcasses, Andrew Perrera and Alex Chinchen for technical assistance, and the two reviewers for their feedback on the first draft of this manuscript. The project was funded by the Natural Environment Research Council, an Advanced Fellowship (NER/J/S/2002/00706) to J.C., a NERC studentship (NER/0329013) with Case Partner the Somerset Otter Group to E.S.S., and Cardiff Undergraduate Research Opportunities Program (CUROP) for A.C. E.S.S. collected and analysed the data in partial fulfilment for the Degree of Doctor of Philosophy at Cardiff University under the joint supervision of J.C. and E.A.C., and all authors jointly revised the thesis chapter into a manuscript. Finally, we dedicate this work to James Williams, Naturalist, Conservationist and staunch supporter of the Cardiff University Otter Project.

Open Access This article is distributed under the terms of the Creative Commons Attribution License which permits any use, distribution, and reproduction in any medium, provided the original author(s) and the source are credited. 


\section{References}

Atkinson D (1994) Temperature and organism size: a biological law for ectotherms? Adv Ecol Res 25:1-58

Atkinson D (1995) Effects of temperature on the size of aquatic ectotherms: exceptions to the general rule. J Thermal Biol 20:61-74

Barber DL, Lockard LL (1973) Some helminths from mink in southwestern Montana, with a checklist of their internal parasites. West North Am Nat 33:53-59

Barreto GR, Macdonald DW (2000) The decline and local extinction of a population of water voles, Arvicola terrestris, in southern England. Int J Mamm Biol 65:110-120

Bonesi L, Palazon S (2007) The American mink in Europe: status, impacts, and control. Biol Conserv 134:470-483

Bonesi L, Chanin P, Macdonald DW (2004) Competition between Eurasian otter Lutra lutra and American mink Mustela vison probed by niche shift. Oikos 106:19-26

Bonhoeffer S, Lenski RE, Ebert D (1996) The curse of the pharoah: the evolution of virulence in pathogens with long lived propagules. Proc R Soc Lond B 263:715-721

Brooks DR, McLennan DA (1993) Parascript: parasites and the language of evolution. Smithsonian Institution Press, Washington, DC

Coombes C (2001) Parasitism: the ecology and evolution of intimate interactions. University of Chicago Press, Chicago

Daszak P, Cunningham AA, Hyatt AD (2000) Emerging infectious diseases of wildlife: threats to biodiversity and human health. Science 287:443-449

Dennehy JJ, Friedenberg NA, Holt RD, Turner PE (2006) Viral ecology and maintenance of novel host use. Am Nat 167:429-439. doi:10.1086/499381

Dunn AM, Dick JTA (1998) Parasitism and epibiosis in native and non-native gammarids in freshwater in Ireland. Ecography 21:593-598

Erickson AB (1944) Helminths of Minnesota Canidae in relation to food habits, and a host list and key to the species reported from North America. Am Midl Nat 32:358-372

Erickson AB (1946) Incidence of worm parasites in Minnesota Mustelidae and host lists and keys to North American species. Am Midl Nat 36:494-509

Ferreras R, Macdonald DW (1999) The impact of American mink Mustela vison on water birds in the upper Thames. J Appl Ecol 36:701-708

Franceschi N, Cornet S, Bollache L, Dechaume-Moncharmont F-X, Bauer A, Motreuil S, Rigaud T (2010) Variation between populations and local adaptation in Acanthocephalan-induced parasite manipulation. Evolution 64:2417-2430

Gandon S (2004) Evolution of multihost parasites. Evolution 58:455-469

Gendron AD, Marcogliese DJ, Thomas M (2012) Invasive species are less parasitized than native competitors, but for how long? The case of the round goby in the Great LakesSt. Lawrence Basin. Biol Invasions 14:367-384

Halliwell EC, Macdonald DW (1996) American mink Mustela vison in the upper Thames catchment: relationship with selected prey species and den availability. Biol Conserv 76:51-56

Harris S, Yalden DW (eds) (2008) Mammals of the British Isles: handbook, 4th edn. Blackwells Scientific Publications, UK
Jeschke JM, Strayer DL (2005) Invasion success of vertebrates in Europe and North America. Proc Nat Acad Sci USA 102:7198-7202

Johnson PTJ, Lund P, Hartson RB, Yoshino T (2009) Community diversity reduces Schistosoma mansoni transmission and human infection risk. Proc R Soc B 276:1657-1663

Kay BH, Boyd AM, Ryan PA, Hall RA (2007) Mosquito feeding patterns and natural infection of vertebrates with Ross River and Barmah forest viruses in Brisbane, Australia. Am J Trop Med Hyg 76:417-423

Keesing F, Belden LK, Daszak P, Dobson A, Harvell CD, Holt RD, Hudson P, Jolles A, Jones KE, Mitchell CE, Myers SS, Bogich T, Ostfeld RS (2010) Impacts of biodiversity on the emergence and transmission of infectious diseases. Nature 468:647-652

Kelly DW, Paterson RA, Townsend CR, Poulin R, Tompkins DM (2009) Parasite spillback: a neglected concept in invasion ecology? Ecology 98:2047-2056

Kennedy CR, Hartvigsen R, Halvorsen O (1991) The importance of fish stocking in the dissemination of parasites throughout a group of reservoirs. J Fish Biol 38:541-552

Kock ND, Kock RA, Wambua J, Mwanzia J (1999) Pathological changes in free-ranging African ungulates during a rinderpest epizootic in Kenya, 1993-1997. Vet Rec 145:527-528

Komar N, Dohm DJ, Turell MJ, Spielman A (1999) Eastern equine encephalitis virus in birds: relative competence of European starlings (Sturnus vulgaris). Am J Trop Med Hyg 60:387-391

Lacerda ACF, Takemoto RM, Tavares-Dias M, Poulin R, Pavanelli GC (2012) Comparative parasitism of the fish Plagioscion souamosisimus in native and invaded river basins. J Parasitol 98:713-717

Macdonald DW, Harrington LA (2003) The American mink: the triumph and tragedy of adaptation out of context. $\mathrm{N} \mathrm{Z} \mathrm{J}$ Zool 30:421-441

Madhavi R (1979) Observations on the occurrence of Allocreadium fasciatusi in Aplocheilus melastigma. J Fish Biol 14:47-58

Madhavi R, Nirmala E, Subbalakshmi C (1998) A population study of the dicrocoeliid trematode Paradistomum orientalis in the garden lizard Calotes versicolor. J Zool 244:489-496

Nituch LA, Bowman J, Beauclerc KB, Schulte-Hostedde AI (2011) Mink farms predict Aleutian disease exposure in wild American mink. PLoS One 6:e21693

Ondračková M, Šimková A, Civáñová K, Vyskočilová M, Jurajda P (2012) Parasite diversity and microsatellite variability in native and introduced populations of four Neogobius species (Gobiidae). Parasitology 139:1493-1505

Pasternak Z, Diamant A, Abelson A (2007) Co-invasion of a Red Sea fish and its ectoparasitic monogenean, Polylabris cf. mamaevi into the Mediterranean: observations on oncomiracidium behaviour and infection levels in both seas. Parasitol Res 100:721-727

Poulin R (1997) Egg production in adult trematodes: adaptation or constraint? Parasitology 114:195-204

Poulin R, Wise M, Moore J (2003) A comparative analysis of adult body size and its correlates in acanthocephalan parasites. Int J Parasitol 33:799-805 
Povilitis A (1998) Characteristics and conservation of a fragmented population of huemul Hippocamelus bisulcus in central Chile. Biol Cons 86:97-104

R Development Core Team (2010) R: a language and environment for statistical computing. R Foundation for Statistical Computing, Vienna

Randall DA, Marino J, Haydon DT, Sillero-Zubiri C, Knobel DL, Tallents LA, Macdonald DW, Laurenson MK (2006) An integrated disease management strategy for the control of rabies in Ethiopian wolves. Biol Conserv 131:151-162

Rauque CA, Viozzi GP, Semenas LG (2003) Component population study of Acanthocephalus tumescens (Acanthocephala) in fishes from Lake Morento, Argentina. Folia Parasitol 50:72-78

Ricciardi A (2007) Are modern biological invasions an unprecedented form of global change? Conserv Biol 21:329-336

Richards DT, Lewis JW (2001) Fecundity and egg output by Toxocara canis in the red fox, Vulpes vulpes. J Helminthol 75:157-164

Roche DG, Leung B, Franco EFM, Torchin ME (2010) Higher parasiterichness, abundance and impact in native versus introduced cichlid fishes. Int J Parasitol 40:1525-1530

Rolfe PF, Boray JC, Nichols P, Collins GH (1991) Epidemiology of paramphistomosis in cattle. Int $\mathrm{J}$ Parasitol 21:813-819

Rudge JW, Lu DB, Fang GR, Wang TP, Basanez MG, Webster JP (2009) Parasite genetic differentiation by habitat type and host species: molecular epidemiology of Schistosoma japonicum in hilly and marshland areas of Anhui Province, China. Mol Ecol 18:2134-2147. doi:10.1111/j.1365-294X. 2009.04181.x

Schmidt KA, Ostfeld RS (2001) Biodiversity and the dilution effect in disease ecology. Ecology 82:609-619
Schneider CA, Rasband WS, Eliceiri KW (2012) NIH Image to ImageJ: 25 years of image analysis. Nat Methods 9:671-675

Sherrard-Smith E, Cable J, Chadwick EA (2009) Distribution of Eurasian otter biliary parasites, Pseudamphistomum truncatum and Metorchis albidus (Family Opisthorchiidae), in England and Wales. Parasitology 136:1015-1022

Shimalov VV, Shimaliv VT (2001) Helminth fauna of the America mink (Mustela vison Schreber, 1777) in Belarussian Polesie. Parasitol Res 87:886-887

Sibly RM, Atkinson D (1994) How rearing temperature affects optimal adult size in ectotherms. Funct Ecol 8:486-493

Simpson VR, Gibbons LM, Khalil LF, Williams JLR (2005) Cholecystitis in otters (Lutra lutra) and mink (Mustela vison) caused by the fluke Pseudamphistomum truncatum. Vet Rec 157:49-52

Torres J, Manas S, Palazon S, Cena JC, Miquel J, Feliu C (2003) Helminth parasites of Mustela lutreola (Linnaeus, 1761) and M. vison Schreber, 1777 in Spain. Acta Parasitol 48:55-59

Torres J, Miquel J, Fournier P, Fournier-Chambrillon C, Liberge M, Fons R, Feliu C (2008) Helminth communities of the autochthonous mustelids Mustela lutreola and M. putorius and the introduced Mustela vison in south-western France. J Helminthol 82:349-355

Vale TG, Spratt DM, Cloonan MJ (1991) Serological evidence of arbovirus infection in native and domesticated mammals on the south coast of New South Wales. Aust J Zool 39:1-7

Ward MP, Lyndal-Murphy M, Baldock FC (1997) Evaluation of a composite method for counting helminth eggs in cattle faeces. Vet Parasitol 73:181-187

Yamaguti S (1971) Synopsis of digenetic trematodes of vertebrates, vol 1. Keigaku, Tokyo 